\title{
$L m x 1 b$ Is Required for Maintenance of Central Serotonergic Neurons and Mice Lacking Central Serotonergic System Exhibit Normal Locomotor Activity
}

\author{
Zhong-Qiu Zhao, ${ }^{1,2 *}$ Michael Scott, ${ }^{6 *}$ Santina Chiechio, ${ }^{1,2}$ Jin-Shan Wang, ${ }^{1,2}$ Kenneth J. Renner, ${ }^{8}$ \\ Robert W. Gereau IV, ${ }^{1,2,5}$ Randy L. Johnson, ${ }^{7}$ Evan S. Deneris, ${ }^{6}$ and Zhou-Feng Chen ${ }^{1,2,3,4}$ \\ ${ }^{1}$ Washington University Pain Center and Departments of ${ }^{2}$ Anesthesiology, ${ }^{3}$ Psychiatry, ${ }^{4}$ Molecular Biology and Pharmacology, and ${ }^{5}$ Anatomy and \\ Neurobiology, Washington University School of Medicine, St. Louis, Missouri 63110, ${ }^{6}$ Department of Neuroscience, School of Medicine, Case Western \\ Reserve University, Cleveland, Ohio 44106, ${ }^{7}$ Department of Biochemistry and Molecular Biology, M. D. Anderson Cancer Center, University of Texas Health \\ Science Center at Houston, Houston, Texas 77030, and ${ }^{8}$ Department of Biology, The University of South Dakota, Vermillion, South Dakota 57069
}

Central serotonergic neurons have been implicated in numerous animal behaviors and psychiatric disorders, but the molecular mechanisms underlying their development are not well understood. Here we generated $L m x 1 b$ (LIM homeobox transcription factor $1 \beta$ ) conditional knock-out mice $\left(\operatorname{Lm} x 1 b^{f f / p}\right)$ in which $L m x 1 b$ was only deleted in Pet1 (pheochromocytoma 12 ETS factor-1)-expressing 5-HT neurons. In $L m x 1 b^{f / f / p}$ mice, the initial generation of central 5-HT neurons appeared normal. However, the expression of both 5-HTspecific and non-5-HT-specific markers was lost in these neurons at later stages of development. The loss of gene expression is concomitant with downregulation of $L m x 1 b$ expression, with the exception of serotonin transporter Sert and tryptophan hydroxylase TPH2, whose expression appears to be most sensitive to $L m x 1 b$. Interestingly, the expression of Pet 1 is tightly coupled with expression of $L m x 1 b$ during later stages of embryonic development, indicating that $L m x 1 b$ maintains Pet 1 expression. In $L m x 1 b^{f / f / p}$ mice, almost all central 5-HT neurons failed to survive. Surprisingly, $L m x 1 b^{f f / p}$ mice survived to adulthood and exhibited normal locomotor activity. These data reveal a critical role of $L m x 1 b$ in maintaining the differentiated status of 5-HT neurons. $L m x 1 b^{f f f p}$ mice with normal locomotor function should provide a unique animal model for examining the roles of central 5-HT in a variety of animal behaviors.

Key words: transcription factor; $\operatorname{Lmx} 1 b$; differentiation; serotonergic neurons; development; locomotor activity

\section{Introduction}

Serotonin [5-hydroxytryptamine (5-HT)] has been implicated in numerous physiological and behavioral activities. In this context, recent genetic studies, especially those originating from phenotypic analysis of 5-HT receptor knock-out mice, have highlighted the important role of the 5-HT system in modulating many developmental processes and psychiatric functions (Scearce-Levie et al., 1999; Gaspar et al., 2003; Gingrich et al., 2003). How the serotonergic neurons are generated and maintain their differentiation during development, however, remains essentially unknown (Goridis and Rohrer, 2002). Recent evidence suggests that a variety of transcription factors [ $L m \times 1 b$ (LIM homeobox transcription factor $1 \beta$ ), Pet1 (pheochromocytoma 12 ETS factor-1), Mash1/Ascl1 (mammalian achaete-schute homolog 1/achaete-

Received Sept. 21, 2006; revised 0ct. 28, 2006; accepted 0ct. 30, 2006.

This work was supported by National Institutes of Health grants (R.W.G., E.D., K.R., R.J., and Z.F.C.). We thank J. Yin, K. H. Zhang, and C. Xiang for technical support, and T. Jessell and Y. Q. Ding for the Lmx1b antibody. We are grateful for D. Wozniak's help with the open field test.

*Z.-Q.Z. and M.S. contributed equally to this work.

Correspondence should be addressed to Zhou-Feng Chen, Departments of Anesthesiology, Psychiatry, Molecular Biology, and Pharmacology, Washington University Pain Center, 660 South Euclid Avenue, St. Louis, M0 63110. E-mail: chenz@wustl.edu.

DOI:10.1523/JNEUROSCI.4143-06.2006

Copyright $\odot 2006$ Society for Neuroscience $\quad$ 0270-6474/06/2612781-08\$15.00/0 scute complex-like 1), Nkx2.2 (NK2 transcription factor-related 2.2), and Gata binding protein 2 (Gata2) and Gata3] are important for the development of 5-HT neurons in the CNS (van Doorninck et al., 1999; Cheng et al., 2003; Ding et al., 2003; Hendricks et al., 2003; Craven et al., 2004; Pattyn et al., 2004; Chen and Ding, 2006). In postmitotic 5-HT neurons, $L m \times 1 b$ and Pet 1 have been implicated as major contributors in the development of 5-HT neurons (Cheng et al., 2003; Ding et al., 2003; Hendricks et al., 2003). Mice lacking Pet1 have a loss of 70-80\% of 5-HT neurons in the CNS (Hendricks et al., 2003), whereas $L m \times 1 b$ knock-out mice lack all central 5-HT neurons (Ding et al., 2003), suggesting that $L m \times 1 b$ and Pet 1 are differentially required for the development of 5-HT neurons. During development, expression of $L m x 1 b$ precedes Pet 1 , and, after a transient expression, Pet 1 is lost in $L m x 1 b$ knock-out mice, raising the possibility that the maintenance of Pet 1 expression is dependent on $L m \times 1 b$ (Cheng et al., 2003; Ding et al., 2003). However, because of difficulties in labeling $L m \times 1 b$-null cells and, thus, in distinguishing between excessive cell death and loss of gene expression in $L m \times 1 b$ knock-out mice, the question of whether $L m \times 1 b$ is required for maintenance of Pet1 expression remains to be clarified.

Serotonergic neurons have been thought to have important roles in multiple developmental processes (Lauder, 1993; Whitaker-Azmitia et al., 1996). Surprisingly, despite the loss of a 
A

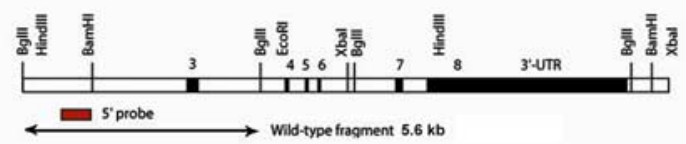

B
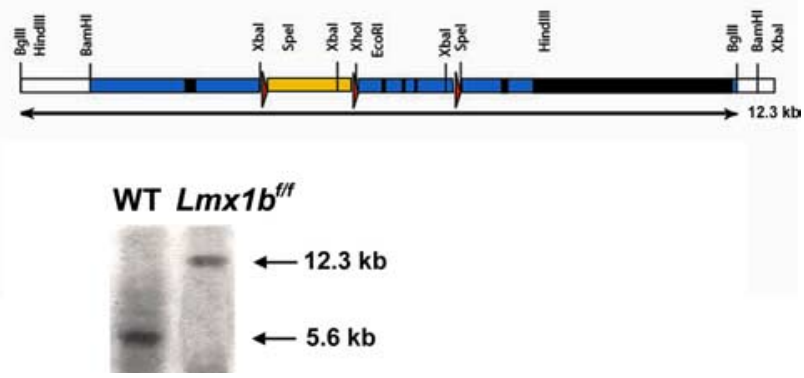

Figure 1. Gene targeting of $L m \times 1 b$. A, Strategy for generating floxed $L m \times 1 b$ mice. Top, Wild-type locus. Exons 3- 8 (black boxes) and introns (white boxes) are shown. The homeodomain is contained within exons 4, 5, and 6. Bottom, Targeting strategy. A loxP-PGKneobpAloxP cassette (blue box with red triangles representing the loxP sites) was inserted into the first Bglll site 5' to exon 4, and an oligonucleotide containing a single loxP site was inserted into the first Bglll site 3' to exon 6 by conventional cloning methods. In both cases, the Bg/ll site was destroyed. In the targeting construct, flanking regions were included (blue) that extended $\sim 3$ $\mathrm{kb} 5^{\prime}$ to the PGKneobpA cassette and $5.5 \mathrm{~kb} 3^{\prime}$ to the $3^{\prime}$ loxP site and an MC1-TK cassette for negative selection. $\boldsymbol{B}$, Southern blot shows a wild-type (WT) band (5.6 kb) and a floxed band $(12.3 \mathrm{~kb})$ after digestion with Bg/ll.

majority of central 5-HT neurons, Pet1 knock-out mice survive and show normal brain morphology (Hendricks et al., 2003). This observation could be attributed to a compensatory effect derived from the remaining 5-HT neurons in Pet1 mutant mice. Because conventional knock-out of $L m \times 1 b$ in mice leads to perinatal lethality, we hypothesized that mice lacking $L m x 1 b$ in 5-HT neurons only (Pet1-expressing neurons) would have no central 5-HT neurons. Mutant mice without central 5-HT neurons, if they survive past birth, would provide a valuable model for determining the function of 5-HT in animal behavior and physiology. Therefore, the goals of the present study were twofold: (1) to evaluate the later role of $L m \times 1 b$ in the development of 5-HT neurons by taking the advantage of the finding that $L m \times 1 b$ expression precedes Pet1 and (2) to assess the function of the central 5-HT neurons in the survival and locomotor activity of mice. To these ends, we generated and analyzed $L m x 1 b$ conditional knockout mice, hereafter referred to as $L m \times 1 b^{f f / p}$ mice, in which $L m \times 1 b$ is deleted only in Pet1-expressing cells.

\section{Materials and Methods}

Generation and genotyping of Lmxlb floxed allele. A 129 genomic clone was used to generate the $L m x 1 b$ targeting vector, and the targeting vector was electroporated into AB1 embryonic stem (ES) cells, followed by G418 selection. Correctly recombined clones were identified by Southern blot and injected into C57BL/6 blastocysts. Pups derived from chimeras mated with C57BL/6 mice were genotyped by PCR using the following primers: for floxed $L m x 1 b 1$, AGG CTC CAT CCA TTC TTC TC; floxed $L m x 1 b 2$, CCA CAA TAA GCA AGA GGC AC; and for wild-type allele, Lmxlb1-a, GAT AGG GCA TTC AAC CAG GAC GAG CAA AGA; and $L m x 1 b-b$, AAA CAG AAG CCA CAG AGA GCC AAG GAG AAG. Southern blotting was performed using genomic DNA purified from tail DNA of wild-type and $L m x 1 b$ mutant mice.

Animals. Lmx $1 b^{f / f / p}$ mice, their wild-type littermates, and ePet-cre (Pet enhancer-cre recombinase) mice aged between 8 and 12 weeks were acclimated to the experimental room and were used for behavioral tests by observers blind to the genotype and the treatment of the animals. All experiments were done in accordance with the guidelines of the university, and the experimental protocols were approved by the Animal Studies Committee at Washington University School of Medicine.

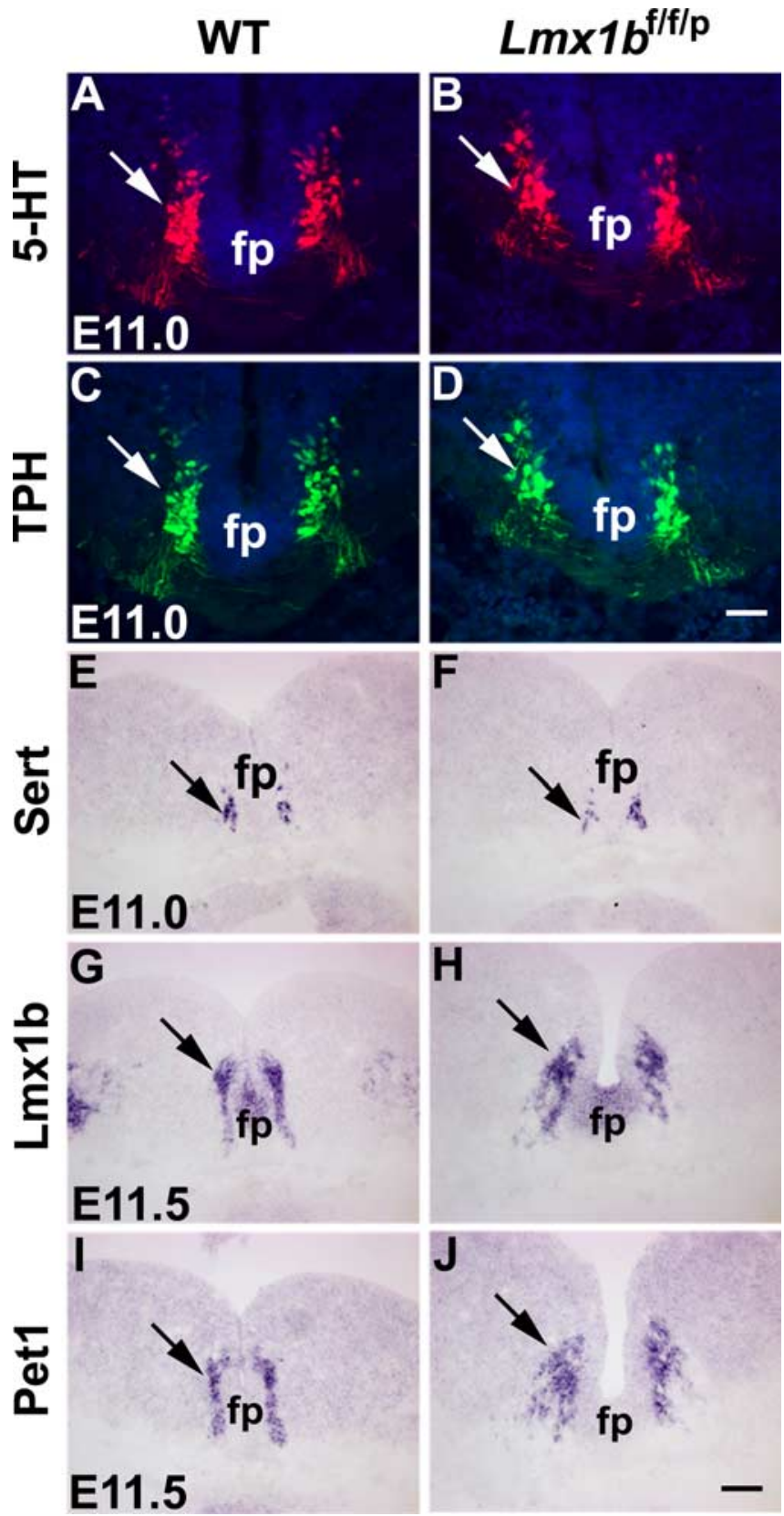

Figure 2. Normal expression of 5-HT, TPH, Sert, Lmx 16 , and Pet1 in the rostral part of the hindbrain of $L m \times 1 b^{f / f / p}$ mice and wild-type (WT) mice. $A, B, 5-H T$ expression detected by immunocytochemical staining in $L m \times 1 b^{t / f / p}$ mice ( $\boldsymbol{B}$, arrow) was similar compared with $L m \times 1 b^{f /+1 p}$ mice $(\boldsymbol{A}$, arrow) at E11. C, $\boldsymbol{D}$, Normal expression of TPH detected by immunocytochemical staining in $L m \times 1 b^{f / f / p}$ mice $(\boldsymbol{D}$, arrow) compared with the control (C, arrow) at E11. $\boldsymbol{E}-\boldsymbol{J}$, Expression of Sert, $L m \times 1 b$, and Pet 1 detected by in situ hybridization was indistinguishable in $L m \times 1 b^{f / f / p}$ mice $(\boldsymbol{F}, \boldsymbol{H}, \boldsymbol{J}$, arrows) compared with wild-type mice $(\boldsymbol{E}, \boldsymbol{G}, \boldsymbol{I}$, arrows). fp, Floor plate. Scale bars: $\boldsymbol{D}, 100 \mu \mathrm{m} ; \boldsymbol{J}, 200 \mu \mathrm{m}$.

5-Bromo-4-chloro-3-indolyl- $\beta$-D-galactopyranoside staining, immunocytochemical staining, and in situ hybridization. 5-Bromo-4-chloro-3indolyl- $\beta$-D-galactopyranoside (X-gal) staining, immunocytochemical staining, and in situ hybridization were performed as described previously (Wang et al., 1998; Chen et al., 2001). The following primary antibodies were used: guinea pig anti-Lmx1b (1:200; a gift from T. Jessell, Columbia University, New York, NY), rabbit anti-5-HT antibody (1: 5000; Immunostar, Hudson, WI), rabbit anti-Cre recombinase (1:1000; Babco, Richmond, CA), rabbit anti-tyrosine hydroxylase (TH) (1:2000; Chemicon, Temecula, CA), mouse anti- $\beta$-galactosidase ( $\beta$-gal) (1:20; 
Developmental Studies Hybridoma Bank, University of Iowa, Iowa City, IA). For secondary antibodies, either secondary antibodies conjugated to cyanine 3 (Cy3) or FITC (1:200; Jackson ImmunoResearch, West Grove, PA) or biotinylated secondary antibodies of appropriate species (Vector Laboratories, Burlingame, CA) were used, followed by $\mathrm{Cy} 3-$ or FITCconjugated streptavidin (1:1000; Jackson ImmunoResearch). The slides were observed using a fluorescence microscopy or a laser scanning confocal microscopy. Hoechst 33258 (Sigma, St. Louis, MO) was used as the blue fluorescent nuclear counterstain.

HPLC. Two-month-old mice of both genotypes were used for HPLC ( $n=4$ for each genotype). Norepinephrine (NE), dihydroxyphenyacetic acid (DOPAC), dopamine (DA), 5-hydroxyindoleacetic acid (5-HIAA), and 5-HT were measured using HPLC with electrochemical detection as described previously with several modifications (Renner and Luine, 1986). The concentrations of the amines and amine metabolites were calculated with respect to the mean peak height values obtained from standard runs set in the internal standard mode using CSW32 software (DataApex, Prague, Czech Republic). The resulting values were corrected for volume and expressed as picograms of amine per milligram of wet tissue weight.

Locomotor activity: motor function. Motor performance was assessed on an accelerating rotarod treadmill (Ugo Basile, Comerio, Italy) as described previously (Malmberg et al., 2003).

Open-field test. Mice were evaluated over a $1 \mathrm{~h}$ period in transparent $(47.6 \times 25.4 \times 20.6$ $\mathrm{cm})$ polystyrene enclosures as described previously (Wozniak et al., 2004).

Statistical analysis. Statistical comparisons were performed using GraphPad Software (San Diego, CA) Prism Software with Student's $t$ test or one-way ANOVA followed by appropriate Fisher's post hoc analysis. Except for the mentioned exceptions, all data were expressed as the mean \pm SEM, and error bars represent SEM. In all cases, $p<0.05$ was considered statistically significant.

\section{Results}

Generation of a floxed $L m x 1 b$ allele and Lmx $1 b^{f / f / p}$ mice

To generate a floxed $L m x 1 b$ allele, we inserted loxP sites around exons 4, 5, and 6 of the $L m x 1 b$ gene using homologous recombination (Fig. 1). The construct was electroporated into $\mathrm{AB} 1 \mathrm{ES}$ cells, and $\sim 10 \%$ of the G418/FIAU resistant clones were correctly targeted. Correctly targeted ES cells were injected into C57BL/6J blastocysts to generate chimeras that transmitted this allele through the germ line. The PGKneobpA cassette was removed by the action of Cre in vivo using deleter cytomegalovirus-cre mice (Fig. 1). To generate Lmx1b conditional knock-out mice, ePet-cre mice (Scott et al., 2005) were mated with $L m \times 1 b^{\text {floxp/floxp }}$ mice to generate $L m \times 1 b^{\text {floxp } /+} / e P e t-c r e$ mice, hereafter referred to as $L m x 1 b^{f /+/ p}$ mice. These mice were subsequently mated with $L m \times 1 b^{\text {floxp/floxp }}$ mice to generate $L m \times 1 b^{\text {floxp/ }}$ floxp/ePet-cre mice or $L m x 1 b^{f / f / p}$ mice. inset, $20 \mu \mathrm{m}$.
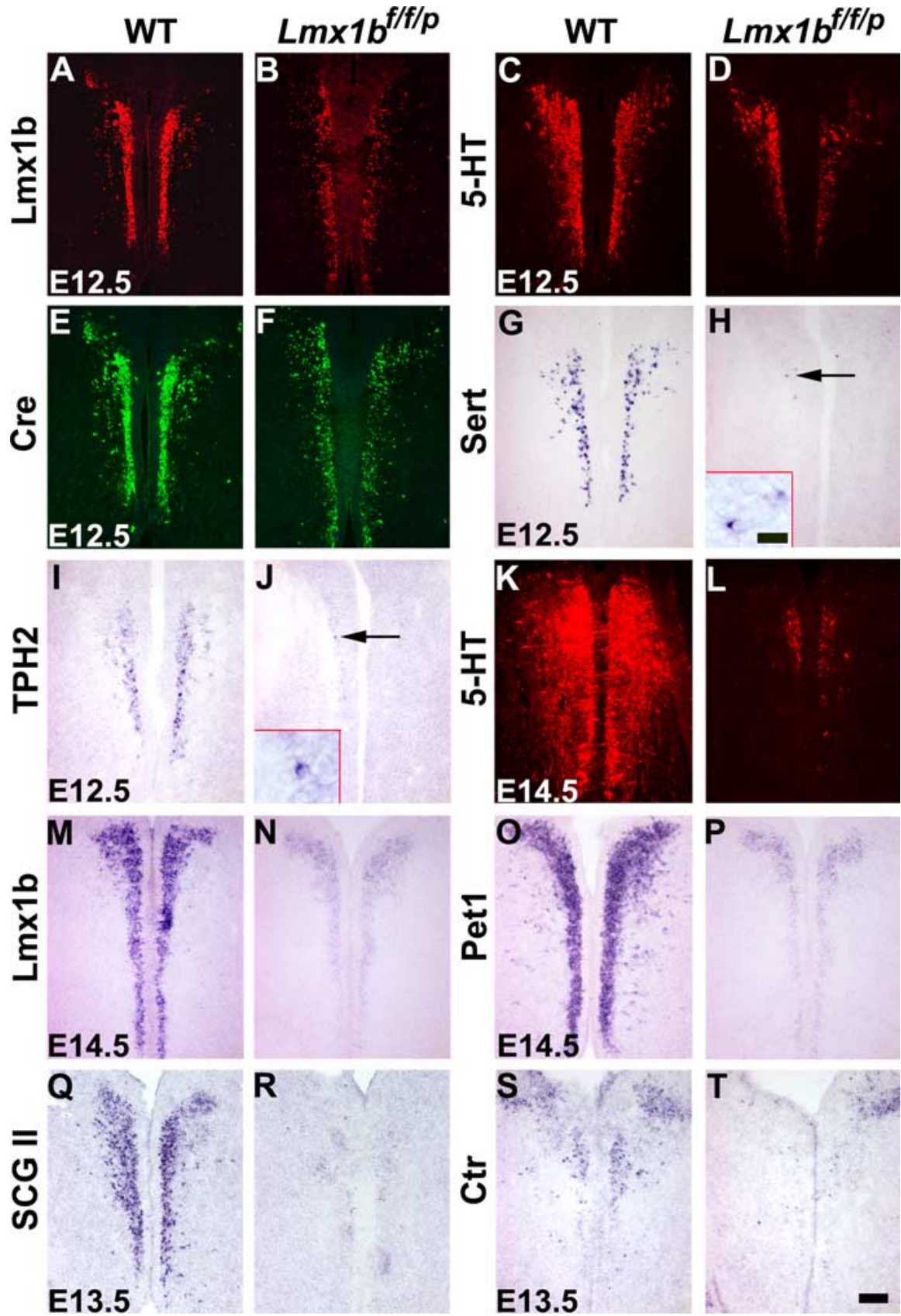

Figure 3. Downregulation and/or loss of molecular markers in the rostral part of the hindbrain of $L m \times 1 b^{f f / f / p}$ mice compared with wild-type mice. $\boldsymbol{A}-\boldsymbol{F}$, Immunocytochemical staining showed that $\operatorname{Lmx} 1 \mathrm{~b}(\boldsymbol{A}, \boldsymbol{B}), 5-\mathrm{HT}(\boldsymbol{C}, \boldsymbol{D})$, and $\operatorname{Cre}(\boldsymbol{E}, \boldsymbol{F})$ expression was downregulated in $L m \times 1 b^{f / f / p}$ mice $(\boldsymbol{B}, \boldsymbol{D}, \boldsymbol{F})$ compared with the control $(\boldsymbol{A}, \boldsymbol{C}, \boldsymbol{E})$ at E12.5. $\mathbf{G}-\mathbf{J}$, Expression of Sert and TPH2 detected by in situ hybridization was virtually lost in $L m \times 1 b^{f / f / p}$ mice $(\boldsymbol{H}, \boldsymbol{J})$ at E12.5. Arrows indicate a few remaining Sert ${ }^{+}$and $\mathrm{TPH}^{+}$cells. Small insets in $\boldsymbol{H}$ and $\boldsymbol{J}$ showed higher magnification of Sert ${ }^{+}$and $\mathrm{TPH}^{+}$cells. $\boldsymbol{K}, \boldsymbol{L}, 5-\mathrm{HT}$ staining was almost lost in $L m \times 1 b^{\mathrm{f} / f / p}$ mice $(\boldsymbol{L})$ by E14.5. $\boldsymbol{M}-\boldsymbol{P}$, Similar downregulation of $L m \times 1 b$ and $\operatorname{Pet} 1$ in $L m \times 1 b^{f f / p}$ mice $(\boldsymbol{N}, \boldsymbol{P})$ compared with wild-type mice $(\boldsymbol{M}, \mathbf{0})$ at E14.5. Q- $\boldsymbol{T}$, Expression of SCGIl and (tr was almost lost in $L m \times 1 b^{f / f / p}$ mice $(\boldsymbol{R}, \boldsymbol{T})$ at E13.5. WT, Wild type. Scale bar: $100 \mu \mathrm{m}$;

Initial generation of central 5-HT neurons is normal in $\operatorname{Lm} \times 1 b^{f / f / p}$ mice

To determine whether central 5-HT neurons were initially generated in $L m \times 1 b^{f / f / p}$ mice, we analyzed the expression of $L m \times 1 b$ and other molecular markers at embryonic day 11.0 (E11.0)E11.25, when 5-HT neurons are first generated in the rostral part of the hindbrain (Ding et al., 2003). Between E11.0 and E11.25, the pattern of 5-HT staining in the rostral hindbrain of $L m \times 1 b^{f / f / p}$ mice exhibited characteristic bilateral organization along the 
midline of the hindbrain, similar to $L m \times 1 b^{f /+/ p}$ or wild-type mice (Fig. $2 A, B$ and data not shown). Tryptophan hydroxylase $(\mathrm{TPH})$ and the serotonin transporter (Sert) also showed similar expression patterns in $L m \times 1 b^{f / f / p}$ mice and wild-type mice (Fig. $2 C-F$ ). In addition, $L m x 1 b$ expression detected by in situ hybridization up to E11.5 was not significantly different in the rostral part of the hindbrain of $L m \times 1 b^{f / f / p}$ mice when compared with wildtype mice (Fig. 2G,H). At this stage, Pet1 expression was also indistinguishable between $L m \times 1 b^{f / f / p}$ mice and wild-type controls (Fig. 2I,J). Examination of these markers in the caudal region of the hindbrain revealed expression pattern in $L m \times 1 b^{f / f / p}$ mice similar to the control mice (data not shown). Together, these data demonstrate that the initial generation of central 5-HT neurons was not affected in $L m \times 1 b^{f / f / p}$ mice.

\section{Downregulation and loss of 5-HT} neuron-specific gene expression in $\operatorname{Lm} x 1 b^{f / f / p}$ mice

At E12.5, Lmx1b expression detected by immunocytochemical staining appeared weaker in $L m \times 1 b^{f / f / p}$ mice when compared with the wild-type control, suggesting that Pet1-cre had already exerted its recombination activity (Fig. $3 A, B$ and data not shown). At this stage, despite the initial normal generation of 5-HT neurons, 5-HT staining was markedly reduced in $L m \times 1 b^{f / f / p}$ mice compared with wild-type mice (Fig. $3 C, D$ and data not shown). Interestingly, Cre staining was also reduced in $L m \times 1 b^{f / f / p}$ mice relative to control, suggesting that expression of Pet1-cre is dependent on $L m x 1 b$ expression (Fig. $3 E, F$ ). In contrast to $L m x 1 b$ and Pet1 expression, expression of Sert and TPH2 [which is expressed only in central 5-HT neurons (Zhang et al., 2004)] detected by in situ hybridization was essentially lost by this stage (Fig. 3G-J). By E14.5, only a few 5-HT-positive $\left(5-\mathrm{HT}^{+}\right)$neurons were present (Fig. $3 K, I$ ), and $L m \times 1 b$ and Pet 1 expression was further reduced compared with the control (Fig. $3 M-P$ ). We also examined the expression of markers that are not related to 5-HT synthesis [secretogranin II (SCGII) (Kato et al., 2000) and calcitonin receptor (Ctr) (Nakamoto et al., 2000)] in $L m \times 1 b^{f / f / p}$ mice and found that expression of SCGII and Ctr was almost lost in $L m x 1 b^{f / f / p}$ mice at E13.5 (Fig. 3Q-T). By E16.5, 5-HT, $L m x 1 b$, Pet 1 , and other markers were rarely detected in $L m \times 1 b^{f / f / p}$ mice (data not shown). These results indicated that $L m \times 1 b$ controls not only the expression of 5-HT-related markers but also non-5HT-related markers.

\section{Examination of $\operatorname{Lmx} 1 b$-null cells in the hindbrain of Lmx1b $b^{f / f / p r}$ mice by X-gal staining}

A loss and downregulation of molecular marker expression could be attributable to cell loss or abnormal cell migration. To distinguish these possibilities, we generated $L m \times 1 b^{+/-} / e P e t-c r e / R O-$ SA26 mice and $L m \times 1 b^{-/-} / e P e t-c r e / R O S A 26$ mice, here referred to $L m \times 1 b^{f /+/ p r}$ and $L m \times 1 b^{f / f / p r}$, respectively. At E16.5 and postnatal day 0 (P0), X-gal staining showed that the presence of presumptive 5-HT neurons was similar in $L m \times 1 b^{f / f / p r}$ mice and control mice (Fig. 4A-H). Moreover, no obvious ectopic X-gal staining was noted in $L m x 1 b^{f / f / p r}$ mice (Fig. $4 A-H$ ). These data
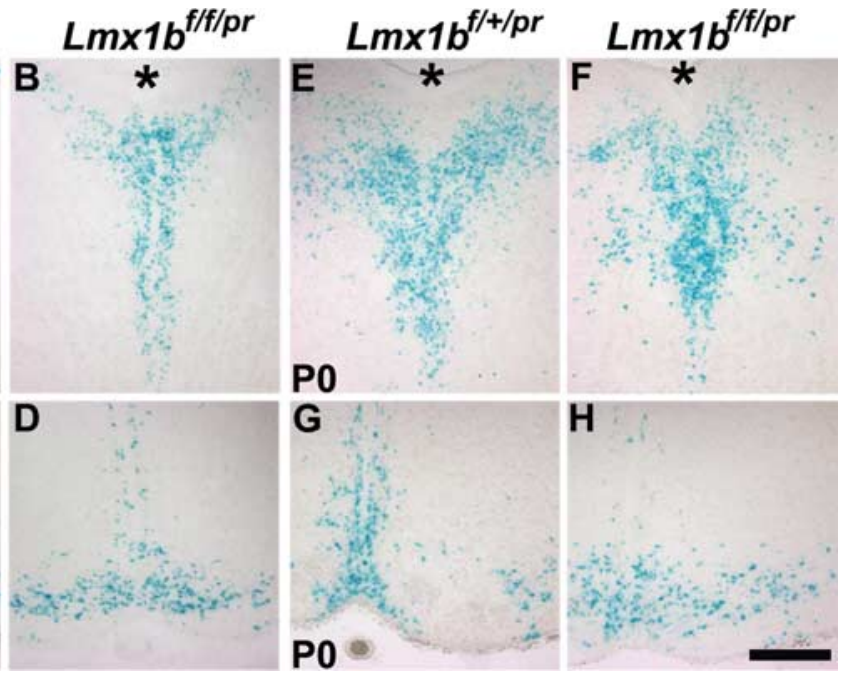

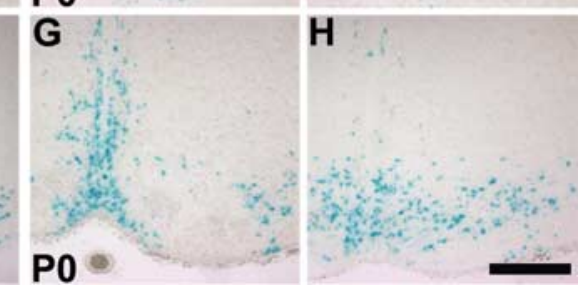

Figure 4. Examination of central 5 -HT neurons by $X$-gal staining. $A-D, X$-gal staining of $5-H T$ neurons in the rostral $(A, B)$ and caudal $(\boldsymbol{C}, \boldsymbol{D})$ part of the hindbrain of $L m \times 1 b^{f /+} / \mathrm{pr}(\boldsymbol{A}, \boldsymbol{C})$ and $\operatorname{Lm} \times 1 b^{f / f / p r}(\boldsymbol{B}, \boldsymbol{D})$ mice at E16.5. X-gal staining patterns were comparable between $L m \times 1 b^{f /+/ p r}$ and $L m \times 1 b^{f / f / p r}$ mice. $\boldsymbol{E}-\boldsymbol{H}, \mathrm{X}$-gal staining of 5 -HT neurons in the rostral $(\boldsymbol{E}, \boldsymbol{F})$ and caudal $(\boldsymbol{G}, \boldsymbol{H})$ part of the hindbrain of $L m \times 1 b^{f /+/ p r}(\boldsymbol{E}, \boldsymbol{G})$ and $L m \times 1 b^{f / f / p r}(\boldsymbol{F}, \boldsymbol{H})$ mice at PO. X-gal staining pattern was also similar in $L m \times 1 b^{f f / f / p r}$ mice compared with $L m \times 1 b^{f /+/ p r}$ mice. Asterisk $\left(^{*}\right)$ indicates the cerebral aqueduct. Scale bar, $100 \mu \mathrm{m}$.

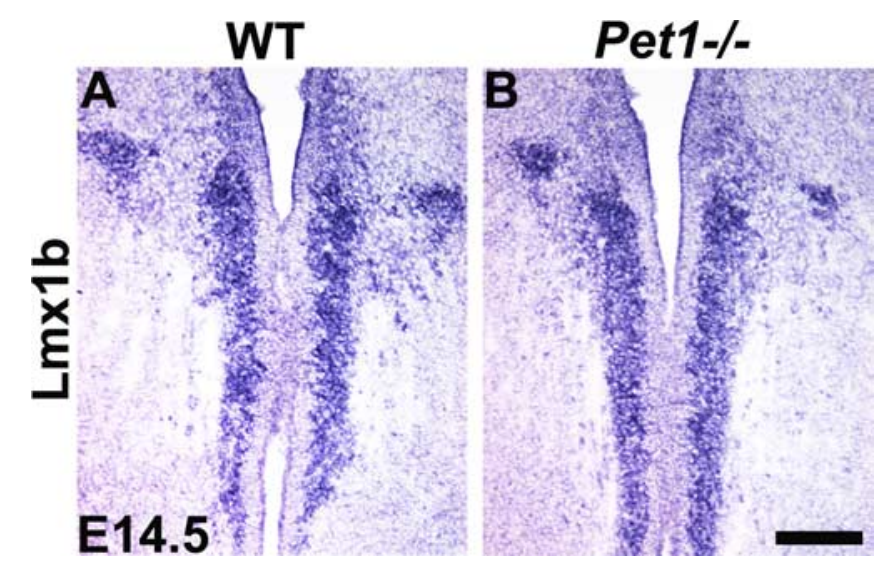

Figure 5. Normal expression of $L m \times 1 b$ in Pet1 mutant mice at E14.5. $A, B$, There was no difference in $L m \times 1 b$ expression detected by in situ hybridization in the rostral part of the hindbrain between wild-type $(\boldsymbol{A})$ and Pet1 mutants $(\boldsymbol{B})$ at E14.5. Scale bar, $100 \mu \mathrm{m}$.

indicated that the loss and downregulation of molecular markers in $L m \times 1 b$ mutants were caused by gene regulation or blockage of differentiation rather than by cell loss or abnormal migration.

\section{Normal expression of $L m x 1 b$ in $P e t 1^{-/-}$mice at later stages of embryogenesis}

We previously showed that $L m \times 1 b$ expression is normal in Pet1 knock-out mice at E11.5 (Ding et al., 2003). To assess whether persistent expression of Pet 1 is required for maintaining $L m \times 1 b$ expression, we examined $L m x 1 b$ expression in Pet 1 knock-out mice at E14.5 and E16.5 before possible abnormal cell death of 5 -HT neurons. At both stages examined, expression of $L m x 1 b$ was indistinguishable between Pet1 knock-out and wild-type mice (Fig. 5A, $B$ and data not shown). These results indicate that $L m \times 1 b$ does not require Pet 1 for its persistent expression at least until E16.5.

\section{Loss of 5-HT neurons in the raphe nuclei of $L m x 1 b^{f / f / p}$ mice} Surprisingly, all $L m \times 1 b^{f / f / p}$ mice survived to adulthood without apparent deficits in motor capability. To examine whether 5-HT 

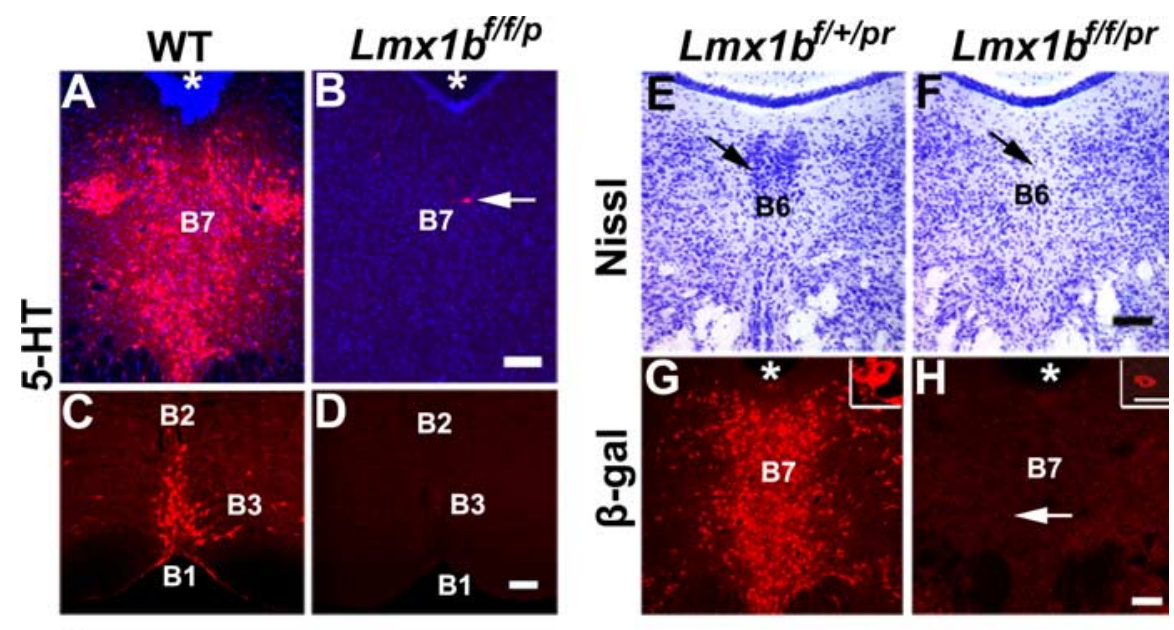

I

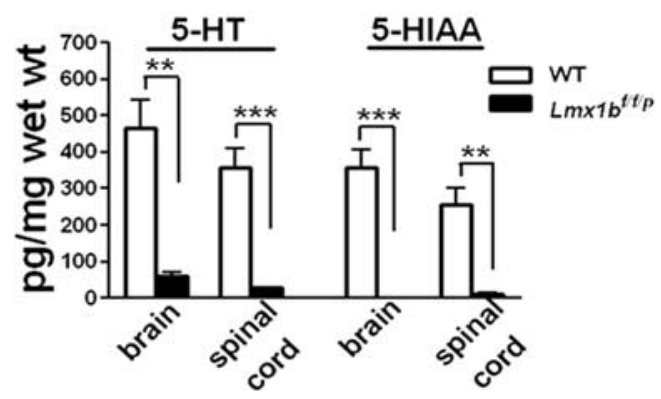

Figure 6. 5-HT neurons are selectively missing in the raphe nuclei of $L m \times 1 b^{f / f / p}$ mice. $A-D$, Immunocytochemical staining of 5 -HT in $B 7(A, B)$ and the caudal part $(B 1-B 3)(C, D)$ of the raphe nuclei of wild-type mice $(\boldsymbol{A}, \boldsymbol{C})$ and $L m \times 1 b^{f / f / p}$ mice $(\boldsymbol{B}, \boldsymbol{D})$. Only a few $5-\mathrm{HT}^{+}$cells were detected in the mutant (arrow in $\boldsymbol{B}$ ). $\boldsymbol{E}, \boldsymbol{F}$, Nissl staining showed the loss of B6 in the raphe nuclei of $\mathrm{Lm} \times 1 b^{f / f / p r}$ mice $(\boldsymbol{F}$, arrow) compared with B6 in wild-type mice (arrow pointing to dark staining of B6 in $\boldsymbol{E})$. $\boldsymbol{G}, \boldsymbol{H}$, Immunocytochemical staining with anti- $\beta$-gal antibody in B7 nucleus of $L m \times 1 b^{f /+/ p r}$ mice $(\boldsymbol{G})$ and $L m \times 1 b^{f / f / p r}$ mice $(\boldsymbol{H})$. Arrows in $\boldsymbol{H}$ indicate a few remaining cells in mutants. Small insets in $\boldsymbol{G}$ and $\boldsymbol{H}$ showed higher magnification of confocal images of anti- $\beta$-gal ${ }^{+}$cells. I, HPLC analysis of 5-HT and 5-HIAA in the brain and spinal cord of $L m \times 1 b^{f / f / p}$ mice $(n=4)$ and wild-type littermates $(n=4)$. There was severe deficiency of the levels of 5-HT and its metabolite 5-HIAA in the CNS of $L m \times 1 b^{f / f / p}$ mice. Two-tailed $t$ test. Asterisk indicates the cerebral aqueduct. WT, Wild type; wet weight, wet tissue weight. Scale bars: $100 \mu \mathrm{m}$; insets, $10 \mu \mathrm{m}$. raphe nuclei is that the presumptive 5-HT neurons might have migrated to other regions. However, we did not find ectopic 5-HT neurons in the $L m \times 1 b^{f / f / p}$ mice. To further assess whether some neurons that failed to express 5-HT markers may have been mislocated, we followed the fate of Pet $1-$ cre $^{+}$cells in Lmxlb $b^{f / f / p r}$ mice by immunochemical staining using an anti- $\beta$ galactosidase antibody and X-gal staining and found that the pattern of $\beta$-gal ${ }^{+}$cells in B nuclei recapitulated the typical 5-HT expression pattern (Fig. 6G). In contrast, only a few $\beta$-gal ${ }^{+}$cells were detected in the raphe nuclei of $L m \times 1 b^{f / f / p r}$ mice (Fig. $6 H$ ). Confocal examination of single $\beta$-gal ${ }^{+}$ cells from $L m \times 1 b^{f /+/ p r}$ mice showed the normal morphology of 5-HT neurons (Fig. 6G, inset), whereas the few remaining $\beta$-gal ${ }^{+}$cells in $L m x 1 b^{f / f / p r}$ mice had no processes or dendrites (Fig. $6 H$, inset). Moreover, the $\beta$-gal ${ }^{+}$cells present in $L m \times 1 b^{f / f / p r}$ mice appeared smaller with respect to $\beta$-gal ${ }^{+}$cells in the controls (Fig. $6 H$, insert). These data strongly suggest that 5-HT neurons are completely lost in the raphe system of adult $L m \times 1 b^{f / f / p}$ mice and the few remaining $5-\mathrm{HT}^{+}$or $\beta$-gal ${ }^{+}$ cells are unlikely to be physiologically normal 5-HT neurons. Our data also suggest that the loss of presumptive 5-HT cells in the raphe nuclei of $L m \times 1 b^{f / f / p}$ mice primarily occurred during postnatal stages.

To determine more quantitatively the level of 5-HT in $L m \times 1 b^{f / f / p r}$ mice, we performed HPLC analysis. The levels of 5-HT and its metabolite 5-HIAA were minimal neurons were present in the raphe nuclei, we analyzed the 5-HT staining pattern in adult $L m x 1 b^{f / f / p}$ and wild-type mice. Serotonergic neurons in the raphe nuclei of the brain are classified into nine groups (B1-B9) based on their anatomical architecture and location (Dahlstroem and Fuxe, 1964). In wild-type mice, 5-HT neurons were present in all $\mathrm{B}$ nuclei of the hindbrain (Fig. 6A, C). In marked contrast, only one or two $5-\mathrm{HT}^{+}$cells were occasionally found in a few sections from $\operatorname{Lm} \times 1 b^{f / f / p}$ mice (Fig. 6B,D). Furthermore, these cells, when present, appeared to be randomly distributed in the various raphe nuclei (Fig. 6B). Consistent with the near absence of 5-HT cell bodies, no ascending or descending 5 -HT fibers in the rostral brain or spinal cord were detected in $L m \times 1 b^{f / f / p}$ mice, whereas wild-type mice had abundant 5-HT fiber staining in both the brain and spinal cord (data not shown). Expression of Pet1, Lmxlb, Sert, TPH and the vesicular monamine transporter VMAT2 were virtually absent in the raphe nuclei of $L m \times 1 b^{f / f / p}$ mice (data not shown).

To examine the distribution and density of cell bodies in the raphe nuclei of wild-type and $L m \times 1 b^{f / f / p}$ mice, we used Nissl staining and found that the cytoarchitecture of B1-B9 nuclei of $L m \times 1 b^{f / f / p}$ mice was altered compared with wild-type control. For example, the cytoarchitecture of B6 (the caudal nucleus raphe dorsalis) in wild-type brainstem sections can be clearly delineated by Nissl staining (Fig. 6E). However, this nucleus was missing in the mutants (Fig. 6 F).

One possible explanation for the absence of 5-HT cells in or undetectable in the brain and spinal cord of $L m \times 1 b^{f / f / p}$ mice compared with wild-type mice (Fig. 6I). The residual 5-HT in the CNS of $L m \times 1 b^{f / f / p r}$ mice may have been derived from circulatory sources or, alternatively, from putative 5-HT neurons located outside of the raphe system (Frankfurt et al., 1981; Weissmann et al., 1987; Ishimura et al., 1988). Nevertheless, our data strongly indicate that the raphe 5-HT neurons are completely lost or nonfunctional in $L m \times 1 b^{f / f / p}$ mice.

\section{Normal expression of TH and NE in the CNS of $\operatorname{Lm} x 1 b^{f / f / p}$ mice}

Pharmacological studies indicated that depletion of central serotonin may affect the level of dopamine and NE (Romaniuk et al., 1989; Koed and Linnet, 2000). To examine whether other neurotransmitter systems are affected in $L m \times 1 b^{f / f / p}$ mice, we performed HPLC studies. HPLC analysis revealed that the levels of DA, DOPAC, and NE in the brain (Fig. 7A) and spinal cord (Fig. 7B) was similar in $L m x 1 b^{f / f / p}$ mice and wild-type mice. In addition, no major structural abnormalities outside the B nuclei were observed in $L m x 1 b^{f / f / p}$ mice (data not shown).

\section{Normal expression of 5-HT in peripheral tissues of $\operatorname{Lm} x \boldsymbol{l b}^{f / f / p}$ mice}

We also examined whether 5-HT expression was affected in the periphery, internal organs, and the dorsal root ganglia (DRGs) of $L m \times 1 b^{f / f / p}$ mice. In the small intestines, the plantar skin (glabrous 
A

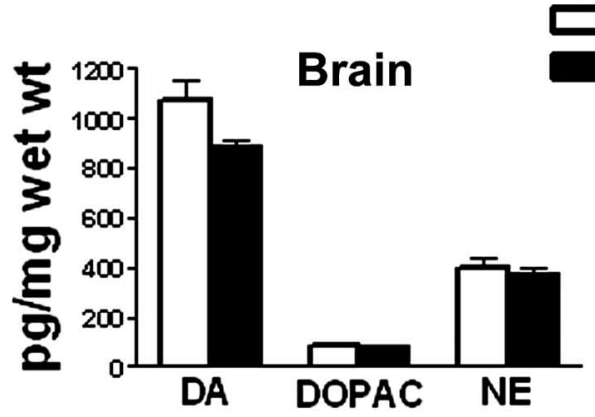

B

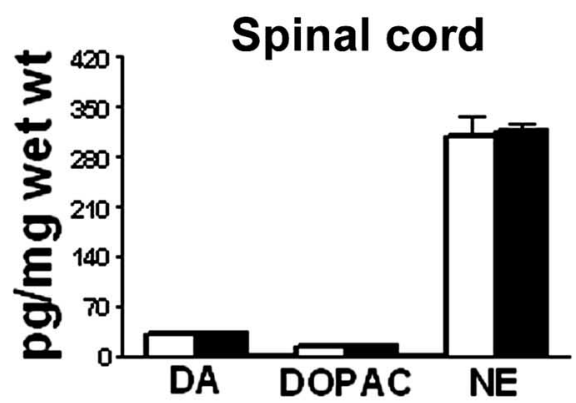

C

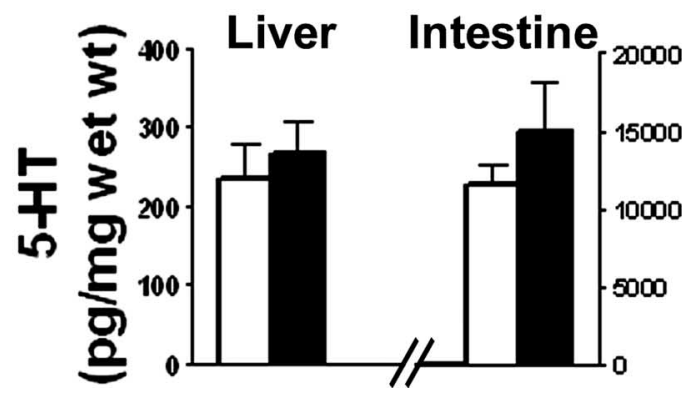

Figure 7. $H P L C$ analysis of DA, DOPAC, and NE in $L m \times 1 b^{f / f / p}$ and wild-type mice. HPLC analysis of two different monoamines and their metabolites levels in the brain $(\boldsymbol{A})$ and spinal cord $(B)$ of 2-month-old wild-type $(n=4)$ and $L m \times 1 b^{f / f / p}(n=4)$ mice. There were no significant differences in the levels of DA and its metabolite DOPAC or NE in the brain or spinal cord of $L m \times 1 b^{f / f / p}$ compared with wild-type mice. C, HPLC analysis of 5-HT levels in the peripheral tissues of wild-type $(n=4)$ and $L m \times 1 b^{f / f / p}(n=4)$ mice. The levels of 5-HT were indistinguishable in the liver and intestine between $L m \times 1 b^{f / f / p}$ and wild-type mice. Wet weight, Wet tissue weight; WT, wild type.

skin of the hindpaw), the adrenal glands, the sciatic nerve, and DRGs, the 5-HT staining pattern in $L m x 1 b^{f / f / p}$ mice was indistinguishable from that in wild-type mice (data not shown). HPLC analysis showed that the levels of 5-HT in liver and intestine of $L m \times 1 b^{f / f / p}$ mice were not significantly different from those in wild-type mice, demonstrating that only 5-HT levels in the CNS were affected (Fig. 7C).

Normal locomotor activity in $\operatorname{Lm} x \mathbf{1} b^{f / f / p}$ mice

To examine motor function of $L m x 1 b^{f / f / p}$ mice, we compared the performance of $L m \times 1 b^{f / f / p}$ and wild-type littermates on the accelerating rotarod test, which allows for the evaluation of coordinated movement and balance. In five different trials, no significant differences between wild-type and $L m \times 1 b^{f / f / p}$ mice were observed in this test (Fig. $8 \mathrm{~A}$ ). We also compared general activity levels of the mice by assessing performance on a $1 \mathrm{~h}$ locomotor activity/open-field test. Activity levels of wild-type and $L m \times 1 b^{f / f / p}$ mice were comparable in terms of total ambulations (whole-
A
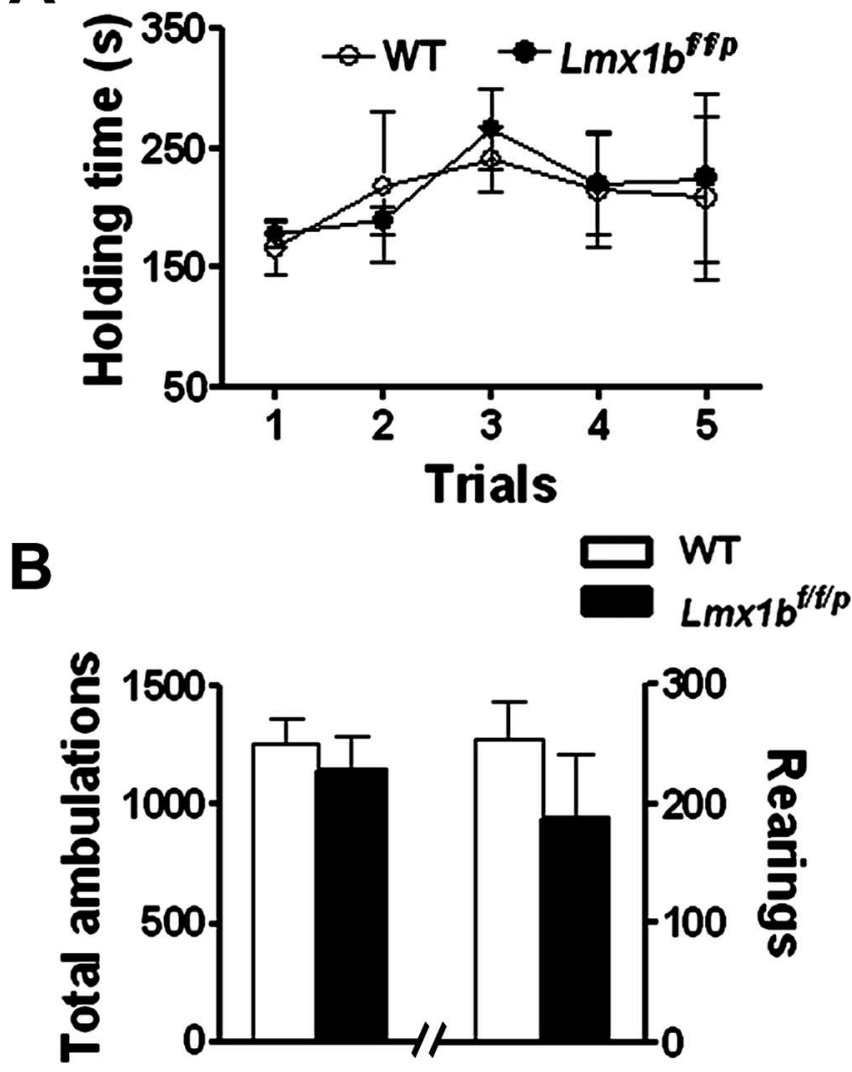

Figure 8. Rotarod and open-field tests. A, Motor performance was tested by using the accelerating rotarod in five consecutive trials with $15 \mathrm{~min}$ interval. Results indicate the time (seconds) that mice remained on the rotating rod before falling. No differences were observed between $L m \times 1 b^{f / f / p}$ mice and wild-type mice. One-way ANOVA followed by Fisher's post hoc analysis. $\boldsymbol{B}$, The general activity levels of the $L m \times 1 b^{f / f / p}$ mice were not different from wild-type mice in total ambulations (whole-body movements) or numbers of rearings quantified over a $1 \mathrm{~h}$ period. Two-tailed $t$ test; $n=9-15$ per genotype. WT, Wild type.

body movements) and the number of rearings (Fig. $8 B$ ). These data demonstrate that the locomotor activity of $L m \times 1 b^{f / f / p}$ mice is normal.

\section{Discussion}

In this study, we used a genetic approach to delete $L m x 1 b$ only in Pet 1 -expressing neurons in mice. We find that $L m \times 1 b$ is essential for maintenance of differentiated status of central 5-HT neurons. In the absence of $L m \times 1 b$, these neurons fail to survive, and subsequently mice lack the entire central 5-HT system.

Surprisingly, these mutant mice survive to adulthood and exhibit normal motor behaviors.

$L m x 1 b$ maintains the differentiation and survival of central 5-HT neurons by differentially regulating downstream gene expression

In the hindbrain of $L m \times 1 b^{f / f / p}$ mice, the initial $L m \times 1 b$ expression and initial generation of 5-HT neurons were normal. Although the time window for normal expression of $L m \times 1 b$ is short, it allows us to assess the effect of the later deletion of $L m \times 1 b$ in the development of 5-HT neurons. This cannot be achieved in conventional $L m x 1 b$ mutants because many 5 -HT or 5 -HT-related genes do not have the chance to be expressed (Ding et al., 2003). In $L m \times 1 b^{f / f / p}$ mice, the downregulation of $L m \times 1 b$ after E12.5 is accompanied by a decrease in 5-HT staining and the downregu- 
lation or loss of 5-HT neuron-specific markers. Interestingly, non-5-HT neuron-specific markers are also lost, suggesting that

the overall differentiation program of 5-HT neurons is blocked by the loss of Lmx1b. These data show that, although 5-HT neurons are generated initially, the program for their further differentiation depends on the persistent presence of $L m x 1 b$. Thus, in $L m \times 1 b^{f / f / p}$ mice, a transient expression of $L m \times 1 b$ is necessary but not sufficient for maintaining the serotonergic phenotype. Our data also indicate that a block of the differentiation of 5-HT neurons eventually results in the abnormal loss of central 5-HT neurons, which occurs primarily during postnatal stages. Together with previous studies (Cheng et al., 2003; Ding et al., 2003), we demonstrate that $L m x 1 b$ is essential not only for the generation of 5-HT neurons but also for maintaining their differentiation and survival during postnatal development.

Analysis of $L m \times 1 b$-null mice showed a loss of Pet 1 expression. However, whether this reflects a loss of cells or gene regulation by $L m x 1 b$ remained unclear (Cheng et al., 2003; Ding et al., 2003). By conditional deletion of $L m x 1 b$ at a later stage of development, we found that expression of Pet1 is remarkably reminiscent of $L m \times 1 b$ in $L m \times 1 b^{f / f / p}$ mice with respect to their downregulation compared with the control. The present study thus provides new evidence indicating that, although initiation of Pet1 is independent of $L m x 1 b$ (Cheng et al., 2003), its persistent expression is tightly coupled with and dependent on expression of $L m x 1 b$. In this regard, Pet 1 differs from other 5-HT-specific markers such as Sert and TPH2, whose expression does not mimic that of Pet1, despite the fact that Pet1 binding sites have been identified in these genes (Hendricks et al., 1999). The fast extinction of Sert and TPH2 expression suggests that these two genes are most sensitive to the level of $L m \times 1 b$ expression. It is likely that $L m \times 1 b$ may directly regulate Sert and TPH2, together with other transcription factors such as Pet1. Given that $L m x 1 b$ expression is not altered in central 5-HT neurons in Pet1 mutants during development, our data suggest that $L m \times 1 b$ is required for Pet1 maintenance but does not require Pet1 for its own maintenance during further differentiation processes of 5-HT neurons (until E16.5 at least).

\section{The central serotonergic system is dispensable for embryonic development and survival of mice}

$L m \times 1 b^{f / f / p}$ mice lack all central 5-HT neurons in the raphe system, whereas 5-HT expression in the periphery is normal. Despite the lack of central 5-HT neurons, $L m \times 1 b^{f / f / p}$ mice survive without apparent developmental abnormalities. These results are surprising given that 5-HT has been implicated in a variety of neuronal developmental processes, including neuronal differentiation and proliferation (Lauder, 1993; Levitt et al., 1997; Azmitia, 2001). In the developing hindbrain of $L m \times 1 b^{f / f / p}$ mice, some 5-HT neurons, as indicated by 5-HT staining, are transiently present between E11.0 and E16.5. One may argue that residual and transient expression of 5-HT may be sufficient to compensate for the loss of 5-HT cells to certain degree. However, because several 5-HTspecific genes such as Sert, which is required for normal function of 5-HT neurons, are almost completely lost at a very early stage, it is unlikely that the remaining 5-HT neurons contribute significantly to neural development and survival of $L m \times 1 b^{f / f / p}$ mice. This is in contrast to Pet1 knock-out mice, in which a relatively large number of 5-HT neurons are maintained (Hendricks et al., 2003). The possibility that some subtle defects in the developing nervous tissues of $L m x 1 b^{f / f / p}$ mice are present cannot be excluded. Nevertheless, our data indicate that the raphe nuclei 5-HT sys- tems are dispensable for overall embryonic development and survival of animals.

\section{The central serotonergic system is not required for normal locomotor activity}

Serotonergic neurons project widely to the spinal cord, including the motor neurons in the ventral horn (Lakke, 1997). Numerous pharmacological studies suggest that 5-HT exerts both facilitatory and inhibitory modulation of locomotor activity (Jacobs and Fornal, 1993, 1997; Schmidt and Jordan, 2000). For example, depletion of central 5-HT by administration of the 5-HT synthesis inhibitor $p$-chlorophenylalanine indicates that 5-HT is involved in postural control and locomotor function in neonatal rats (Myoga et al., 1995; Pflieger et al., 2002). The evidence also showed that the central pattern generators for locomotion are subject to the influence of descending pathways, including 5-HT (Vinay et al., 2002). In contrast, we found that coordination and balance of motor activity are normal in adult $L m \times 1 b^{f / f / p}$ mice, indicating that the central 5-HT system is not required for acquisition of locomotor function. Several reasons may be offered to explain a discrepancy in motor behavior between genetic deletion and pharmacological perturbation. One possibility is that depletion of 5-HT by pharmacological treatments may have nonspecific effects that also interfere with other neurotransmitter pathways that are required for locomotor activity. Alternatively, other molecular pathways or neurotransmitter systems may compensate for the lack of 5-HT required for locomotor activity. A recent study showed that ablation of neuropeptide Y-expressing neurons by injection of diphtheria toxin in hypothalamic neurons of adult mice, but not in neonatal mice, caused feeding deficits ( $\mathrm{Lu}-$ quet et al., 2005). A network-based compensatory mechanism has been suggested to explain this observation (Luquet et al., 2005). It is thus conceivable that similar mechanisms could be involved in such adaptive changes in the neural circuits, especially during the critical postnatal period of development, and thereby result in a normal motor behavior of adult mutant mice lacking the central 5-HT system. Future studies using temporally controlled deletion of central 5-HT system may settle this issue. Nonetheless, the fact that $L m x 1 b^{f / f / p}$ mice have normal locomotor activity provides a unique animal model for conducting a battery of behavioral tests that are designed to examine the role of the central 5-HT system in many physiological and behavioral activities, including depression, aggression, sexual behavior, and pain perception.

\section{References}

Azmitia EC (2001) Modern views on an ancient chemical: serotonin effects on cell proliferation, maturation, and apoptosis. Brain Res Bull 56:413-424.

Chen ZF, Ding YQ (2006) Transcriptional control of the development of central serotonergic neurons. In: Transcription factors in the nervous system (Thiel G, ed), pp 143-156. Weinheim, Germany: Wiley-VCH Verlag.

Chen ZF, Rebelo S, White F, Malmberg AB, Baba H, Lima D, Woolf CJ, Basbaum AI, Anderson DJ (2001) The paired homeodomain protein DRG11 is required for the projection of cutaneous sensory afferent fibers to the dorsal spinal cord. Neuron 31:59-73.

Cheng L, Chen CL, Luo P, Tan M, Qiu M, Johnson R, Ma Q (2003) Lmxlb, Pet-1, and Nkx2.2 coordinately specify serotonergic neurotransmitter phenotype. J Neurosci 23:9961-9967.

Craven SE, Lim KC, Ye W, Engel JD, de Sauvage F, Rosenthal A (2004) Gata2 specifies serotonergic neurons downstream of sonic hedgehog. Development 131:1165-1173.

Dahlstroem A, Fuxe K (1964) Evidence for the existence of monoaminecontaining neurons in the central nervous system. I. Demonstration of 
monoamines in the cell bodies of brain stem neurons. Acta Physiol Scand 62 [Suppl 232]:231-255.

Ding YQ, Marklund U, Yuan W, Yin J, Wegman L, Ericson J, Deneris E, Johnson RL, Chen ZF (2003) Lmxlb is essential for the development of serotonergic neurons. Nat Neurosci 6:933-938.

Frankfurt M, Lauder JM, Azmitia EC (1981) The immunocytochemical localization of serotonergic neurons in the rat hypothalamus. Neurosci Lett 24:227-232.

Gaspar P, Cases O, Maroteaux L (2003) The developmental role of serotonin: news from mouse molecular genetics. Nat Rev Neurosci 4:1002-1012.

Gingrich JA, Ansorge MS, Merker R, Weisstaub N, Zhou M (2003) New lessons from knockout mice: the role of serotonin during development and its possible contribution to the origins of neuropsychiatric disorders. CNS Spectr 8:572-577.

Goridis C, Rohrer H (2002) Specification of catecholaminergic and serotonergic neurons. Nat Rev Neurosci 3:531-541.

Hendricks T, Francis N, Fyodorov D, Deneris ES (1999) The ETS domain factor Pet- 1 is an early and precise marker of central serotonin neurons and interacts with a conserved element in serotonergic genes. J Neurosci 19:10348-10356.

Hendricks TJ, Fyodorov DV, Wegman LJ, Lelutiu NB, Pehek EA, Yamamoto B, Silver J, Weeber EJ, Sweatt JD, Deneris ES (2003) Pet-1 ETS gene plays a critical role in 5-HT neuron development and is required for normal anxiety-like and aggressive behavior. Neuron 37:233-247.

Ishimura K, Takeuchi Y, Fujiwara K, Tominaga M, Yoshioka H, Sawada T (1988) Quantitative analysis of the distribution of serotoninimmunoreactive cell bodies in the mouse brain. Neurosci Lett 91:265-270.

Jacobs BL, Fornal CA (1993) 5-HT and motor control: a hypothesis. Trends Neurosci 16:346-352.

Jacobs BL, Fornal CA (1997) Serotonin and motor activity. Curr Opin Neurobiol 7:820-825.

Kato A, Kammen-Jolly K, Fischer-Colbie R, Humpel C, Schrott-Fischer A, Marksteiner J (2000) Co-distribution patterns of chromogranin B-like immunoreactivity with chromogranin A and secretoneurin within the human brainstem. Brain Res 852:444-452.

Koed K, Linnet K (2000) Opposing changes in serotonin and norepinephrine transporter mRNA levels after serotonin depletion. Eur Neuropsychopharmacol 10:501-509.

Lakke EA (1997) The projections to the spinal cord of the rat during development: a timetable of descent. Adv Anat Embryol Cell Biol 135:I-XIV, $1-143$.

Lauder JM (1993) Neurotransmitters as growth regulatory signals: role of receptors and second messengers. Trends Neurosci 16:233-240.

Levitt P, Harvey JA, Friedman E, Simansky K, Murphy EH (1997) New evidence for neurotransmitter influences on brain development. Trends Neurosci 20:269-274.

Luquet S, Perez FA, Hnasko TS, Palmiter RD (2005) NPY/AgRP neurons are essential for feeding in adult mice but can be ablated in neonates. Science 310:683-685.

Malmberg AB, Gilbert H, McCabe RT, Basbaum AI (2003) Powerful antinociceptive effects of the cone snail venom-derived subtype-selective NMDA receptor antagonists conantokins G and T. Pain 101:109-116.
Myoga H, Nonaka S, Matsuyama K, Mori S (1995) Postnatal development of locomotor movements in normal and para-chlorophenylalaninetreated newborn rats. Neurosci Res 21:211-221.

Nakamoto H, Soeda Y, Takami S, Minami M, Satoh M (2000) Localization of calcitonin receptor mRNA in the mouse brain: coexistence with serotonin transporter mRNA. Brain Res Mol Brain Res 76:93-102.

Pattyn A, Simplicio N, van Doorninck JH, Goridis C, Guillemot F, Brunet JF (2004) Ascl1/Mash1 is required for the development of central serotonergic neurons. Nat Neurosci 7:589-595.

Pflieger JF, Clarac F, Vinay L (2002) Postural modifications and neuronal excitability changes induced by a short-term serotonin depletion during neonatal development in the rat. J Neurosci 22:5108-5117.

Renner K, Luine V (1986) Analysis of temporal and dose-dependent effects of estrogen on monoamines in brain nuclei. Brain Res 366:64-71.

Romaniuk A, Strzelczuk M, Wieczorek M (1989) Serotonin depletion with P-chlorophenylalanine in the cat: effects on carbachol-induced defensive behavior and regional brain amine content. Acta Neurobiol Exp (Wars) 49:130-140.

Scearce-Levie K, Chen JP, Gardner E, Hen R (1999) 5-HT receptor knockout mice: pharmacological tools or models of psychiatric disorders. Ann NY Acad Sci 868:701-715.

Schmidt BJ, Jordan LM (2000) The role of serotonin in reflex modulation and locomotor rhythm production in the mammalian spinal cord. Brain Res Bull 53:689-710.

Scott MM, Wylie CJ, Lerch JK, Murphy R, Lobur K, Herlitze S, Jiang W, Conlon RA, Strowbridge BW, Deneris ES (2005) A genetic approach to access serotonin neurons for in vivo and in vitro studies. Proc Natl Acad Sci USA 102:16472-16477.

van Doorninck JH, van Der Wees J, Karis A, Goedknegt E, Engel JD, Coesmans M, Rutteman M, Grosveld F, De Zeeuw CI (1999) GATA-3 is involved in the development of serotonergic neurons in the caudal raphe nuclei. J Neurosci 19:RC12(1-8).

Vinay L, Brocard F, Clarac F, Norreel JC, Pearlstein E, Pflieger JF (2002) Development of posture and locomotion: an interplay of endogenously generated activities and neurotrophic actions by descending pathways. Brain Res Brain Res Rev 40:118-129.

Wang HU, Chen ZF, Anderson DJ (1998) Molecular distinction and angiogenic interaction between embryonic arteries and veins revealed by ephrin-B2 and its receptor Eph-B4. Cell 93:741-753.

Weissmann D, Belin MF, Aguera M, Meunier C, Maitre M, Cash CD, Ehret M, Mandel P, Pujol JF (1987) Immunohistochemistry of tryptophan hydroxylase in the rat brain. Neuroscience 23:291-304.

Whitaker-Azmitia PM, Druse M, Walker P, Lauder JM (1996) Serotonin as a developmental signal. Behav Brain Res 73:19-29.

Wozniak DF, Hartman RE, Boyle MP, Vogt SK, Brooks AR, Tenkova T, Young C, Olney JW, Muglia LJ (2004) Apoptotic neurodegeneration induced by ethanol in neonatal mice is associated with profound learning/ memory deficits in juveniles followed by progressive functional recovery in adults. Neurobiol Dis 17:403-414.

Zhang X, Beaulieu JM, Sotnikova TD, Gainetdinov RR, Caron MG (2004) Tryptophan hydroxylase-2 controls brain serotonin synthesis. Science 305:217. 